\title{
AMOR ERÓTICO E CASTIDADE NO HIPÓLITO DE EURÍPIDES
}

\begin{abstract}
Flávio Ribeiro de Oliveira ${ }^{\star}$
Universidade Estadual de Campinas

RÉSUMÉ: Dans cet article, j'analyse comment, dans l'Hippolyte d'Euripide, la notion de passion érotique est conçue comme une maladie et quelles sont ses relations avec la notion de chasteté.
\end{abstract}

MOTS-CLÉS: Euripide; Hippolyte; amour érotique.

retendo discutir neste texto ${ }^{1}$ as noções de amor erótico e castidade no Hipólito de Eurípides. Contudo, antes de tratar do Hipólito - e para que compreendamos melhor como operam ali essas noções - analiso brevemente alguns aspectos da ode de Safo conhecida como Ode a Anactória (fr. 31 Voigt), conservada pelo Tratado sobre o sublime, obra de autor desconhecido (outrora atribuída a Longino).

$\mathrm{Na}$ ode, uma mulher - o eu poético - observa um casal (um rapaz e uma moça); atraída pela moça, ela afirma que, quando a vê, sofre uma série de reações físicas. Interessa-nos, aqui, a sintomatologia descrita pela poeta. Essas reações são: a) perturbação cardíaca (kardían en stéthesin eptóaisen, verso 6); b) mutismo (kàm mèn glôssa éage, verso 9 ); c) calor, sensação de fogo sob a pele (lépton d'aútika khrôi pûr upadedrómeken, versos 9-10); d) cegueira (oppátessi d' oud' èn óremm', verso 11); e) zumbido nos ouvidos (epirrómbeisi d'ákouai, versos 11-12); f) suor frio que lhe inunda o corpo

\footnotetext{
^frasp@iel.unicamp.br

${ }^{1}$ Apresentado oralmente em 2010, na "IX Semana de Pós-Graduação em Estudos Clássicos e Medievais: Metamorfoses de Eros", promovida pelo NEAM da FALE/ FAFICH - UFMG. O texto aqui publicado conserva suas marcas de oralidade.
} 
(kád dé m’ ídros psîkhros kakkhéetai, verso 13); g) tremor por todo o corpo (trómos dè paîsan ágrei, versos 13-14); h) pele esverdeada (khlorotéra dè poías émmi, versos 14-15). ${ }^{2}$ Muitos desses sintomas já apareciam em Homero: são, na Ilíada e na Odisseia, reações do organismo provocadas pelo pesar, pela preocupação, pelo pavor, pela dor física. Em Homero, os sintomas aparecem isolados (raramente formando um par - por exemplo, tremor e palidez juntos). Ora, na ode de Safo há duas diferenças importantes: aqui, todos esses sintomas aparecem juntos, ao mesmo tempo, na mesma pessoa e - novidade fundamental - como sintomas não de dor, pesar, susto etc., mas de paixão amorosa (o que nunca ocorria em Homero).

Contudo, um eventual leitor que tomasse apenas esses versos talvez pensasse que a ode descreve uma pessoa doente. Essa mulher, que está esverdeada, tomada de tremedeira, muda, com uma névoa sobre os olhos, com taquicardia, com zumbido nos ouvidos, queimando de calor - e suando frio - sofre com alguma enfermidade!

Portanto, em sua Ode a Anactória, Safo reúne, pela primeira vez na poesia ocidental, todos aqueles sintomas (que já apareciam individualmente em Homero) e os atribui à paixão amorosa - e podemos afirmar que, aqui, ela inequivocamente caracteriza a paixão amorosa como uma patologia: o estado dessa mulher é patológico; ela está amando e está doente...

Passemos ao Hipólito de Eurípides. O leitor que buscar um manual de literatura grega e procurar o resumo da ação da peça inevitavelmente encontrará mais ou menos o seguinte: Afrodite está irritada com Hipólito porque ele a despreza e venera apenas Ártemis, deusa casta. Como vingança, a Cípria faz Fedra, a madrasta de Hipólito, se apaixonar por ele. A ação da tragédia continua até o desfecho ruinoso; contudo detenhamo-nos aqui: o que nos interessa particularmente é esse apaixonar-se de Fedra.

Quando Afrodite faz referência a Fedra pela primeira vez na peça, diz que a jovem padece de uma doença (nóson, v. 40). Mais tarde, o Coro alude ao fato de ela jazer alquebrada em estado doentio (teiroménan noserâi koítai, v. 131). No diálogo do Coro com a nutriz, diz-se que ela está sem comer (abrosíai stómatos, v. 136-7), que seu corpo apresenta cor alterada (démas allókhroon, v. 175), que ela sofre de um páthos ${ }^{3}$ oculto.

\footnotetext{
${ }^{2}$ Khlorós é um verde pálido, esverdeado. É a cor que assume quem está muito doente ou levou um grande susto (em nossa cultura, diríamos que esse indivíduo está "pálido").

${ }^{3}$ Lembremo-nos de que páthos inclui nossa noção de paixão, mas também nossa noção de doença. No vocabulário médico, por exemplo, disenteria era dusenterikà páthẹ.
} 
Quando aparece em cena, Fedra está prostrada, estendida em uma maca de doente, carregada por criadas. Afirma que sofre de fraqueza nos membros (lélumai meléon súndesma, v. 199), de peso na cabeça (barù moi kephalês epíkranon, v. 201); o Coro menciona o estado de debilidade geral e de consumpção do corpo de Fedra (hos astheneî te kaì katéxantai démas, v. 274). Enfim, sua condição é descrita claramente como uma nósos.

Além disso, quando Fedra fala, aquilo que ela diz parece não ter sentido, e a nutriz pensa em loucura: tal fala é inspirada pela manía (v. 214), é uma fala demente (paráphron épos, v. 232). O Tratado sobre o sublime (X, 3), ao comentar a ode de Safo, percebeu que se tratava de uma afecção que atingia tanto a alma (tèn psukhén) como o corpo (tò sôma) do eu poético.

Portanto, Fedra padece de uma doença que lhe perturba o corpo e a mente. $\mathrm{O}$ vocabulário da moléstia (e da loucura, que também era vista como uma nósos) está presente de forma marcante em todo esse diálogo entre Fedra, a nutriz e o Coro. Nósos, noseîn e termos cognatos aparecem nos versos 176, 179, 186, 205, 269, 279, 293 e 294. Enfim, é inegável que Fedra está doente. A questão, para o Coro, para a nutriz e para nós, leitores modernos, é "que doença é esta?". O Coro apresenta explicitamente a questão: quer saber hétis estin he nósos (v. 269). E muitos leitores modernos - leitores que conhecem a Ode a Anactória e que agora leem o Hipólito - respondem sem hesitar que não há mistério: tanto a mulher da ode de Safo quanto Fedra estão apaixonadas. Essa é a doença. Aquelas moças padecem de amor.

Pois bem, pretendo demonstrar que essa resposta não é exata. Fedra não está apaixonada por Hipólito. A ideia de "paixão" e de "apaixonar-se" implica, em nossa língua e em nossa cultura, um envolvimento afetivo profundo. Uma moça pode dizer a seus pais, durante um jantar, "estou apaixonada por um rapaz". A paixão está associada a noções de ternura, amizade, afeição: ela implica um compromisso afetivo terno e profundo que está excluído no caso de Fedra. Fedra não gosta de Hipólito; Hipólito é seu inimigo. A doença dela é desejo sexual - só e tudo isso. Fedra deseja Hipólito sexualmente. Sofre na alma e em todo o corpo por desejo de fazer sexo com Hipólito. E é justamente esse o domínio de Afrodite.

Com efeito, Afrodite não é a deusa do "amor" tal como entendemos hoje essa noção: ${ }^{4}$ é a deusa do amor carnal, é a deusa do

\footnotetext{
${ }^{4}$ Aliás, aquilo que em nossa língua e nossa cultura chamamos “amor" não é um afeto imutável que sempre existiu, idêntico a si mesmo, em toda a História e entre todos os povos: a ideia de amor evolui e se metamorfoseia. Pode-se fazer uma História do amor, uma História dos afetos - mas isso é uma outra história.
} 
sexo. Seu domínio é o da paixão erótica. Afrodite é o sexo em estado bruto, é a atração erótica irresistível e não está, essencialmente, vinculada a afeição, ternura, namoro, casamento - embora de modo geral se associe secundariamente a essas noções (pois uma das funções sociais do casamento implica o sexo e, do ponto de vista afetivo, a atividade sexual pode implicar ternura). Eu diria que, no que diz respeito ao modo como o grego concebia a esfera de ação de Afrodite, o sexo pode estar ligado às concepções de casamento ou de ternura por acidente, e não por essência.

Como afirmamos, o domínio de Afrodite é o da paixão erótica, do sexo. O autor do Tratado sobre o sublime, ao falar a respeito dos sintomas descritos na ode de Safo, refere-se a eles justamente como tà sumbaínonta taîs erotikaîs maníais pathémata (as paixões - ou os sofrimentos - aderentes à loucura erótica). A paixão erótica - tà erotikà pathémata - que devasta corpo e alma é vista, no pensamento poético grego, como uma doença, como uma nósos. O desejo sexual é, então, concebido como enfermidade. Ora, uma questão se impõe a nós, leitores, e a todos aqueles que padecem dessa doença: se é doença, qual é o remédio?

No Hipólito, a nutriz, ao descobrir que a doença de sua senhora é desejo sexual, afirma que tem um remédio (phármakon, v. 516) para o mal. Esse remédio, todavia, é um filtro amoroso (phíltra, v. 509). Ora, um phíltron era um meio mágico de provocar desejo erótico em alguém (e não de eliminar, de curar o desejo erótico). O remédio proposto pela nutriz para a doença de Fedra, portanto, é tornar doente também Hipólito: que a doença seja recíproca. A nutriz parece supor que a doença de Fedra não tem cura e que, portanto, a única saída seria atingir igualmente a Hipólito. Tal phármakon seria destinado ao mancebo para que este também adoeça, e não para curar Fedra.

O que está em questão é um problema moral, no sentido grego (de uma moral eminentemente prática). A questão é: o que fazer quando se é acometido de desejo sexual? O que fazer com essa paixão erótica que nos atormenta?

Uma solução possível seria eliminar o desejo. Contudo, isso parece impossível aos olhos da nutriz; a paixão erótica vem de Afrodite, é divina, é inelutável. Não há remédio para eliminar o desejo. Daí a solução proposta: se Fedra não pode eliminar o desejo, deve então satisfazê-lo. É simples. Se Hipólito também desejar Fedra, Fedra poderá satisfazer seu desejo. Essa solução do impasse moral provocado pela paixão erótica - uma solução bem grega - não foi a solução que triunfou em nossa cultura. 
A resposta que, entre nós, triunfou culturalmente (pelo menos no plano ideológico) foi uma terceira via: entre eliminar o desejo e satisfazer o desejo, há uma atitude intermediária: reconhecendo que o desejo é inevitável (e que, portanto, não é possível eliminá-lo), cumpre resistir a ele. Tal resposta pode ser encontrada em Platão. Numa das mais belas passagens do Górgias (493a), afirma-se que nosso corpo (sôma) é um túmulo (sêma). A alma - que é boa e constitui a melhor parte de nós mesmos - é prisioneira do corpo - que é inferior e consiste no pior de nós mesmos. Os desejos do corpo têm um problema: são insaciáveis. Nesse passo, Platão apresenta a célebre imagem do tonel furado - alusão ao tonel das Danaides: elas foram condenadas, no Hades, a encher com água, perpetuamente, um tonel cheio de furos. Aquele que se dedica a satisfazer sempre os desejos (epithumíai) do corpo está na mesma situação que as Danaides: ele nunca será capaz de encher definitivamente o tonel, pois a água que nele é vertida escapa imediatamente pelos furos. Os desejos do corpo são um tonel furado.

Uma metamorfose moderna da imagem do tonel das Danaides é a figura mítica de Don Juan, paradigma da insaciabilidade da paixão erótica: ele jamais fica satisfeito; imediatamente após a consumação de uma experiência sexual, ele já é impelido a buscar outras. Na versão provavelmente mais célebre dessa personagem - o Don Giovanni do libreto de Lorenzo da Ponte para a ópera homônima de Mozart Leporello diz a Dona Elvira (que está irritada porque Don Giovanni a havia traído): "Non siete voi, non foste e non sarete/ né la prima, né l'ultima" (ato I, cena 5). O tonel nunca ficou e jamais ficará definitivamente completo: Don Giovanni está fadado a se esfalfar incessantemente para enchê-lo, numa busca perpétua, inesgotável e vã da satisfação do desejo sexual.

Mas retornemos ao problema que nos ocupa: o desejo sexual que, no pensamento platônico, se inclui nessa categoria dos prazeres do corpo - por um lado não pode ser simplesmente suprimido, pois é irresistível e, por outro lado, nunca será completamente saciado. Se o satisfaço, ele volta depois de algum tempo e devo me empenhar para satisfazê-lo novamente, num movimento perpétuo, como no caso do tonel que nunca fica definitivamente cheio: a água que lá coloco sempre escapa pelos furos.

Diante dessa dupla impossibilidade - impossibilidade de eliminar e impossibilidade de saciar a paixão erótica - a resposta platônica é mais ou menos a seguinte: não passe sua vida a se esforçar, em vão, para satisfazer os desejos do corpo, pois as paixões sensíveis são o que há de 
pior nos homens; cuide de sua alma, que é o melhor de você. Essa resposta moral ao problema do desejo erótico leva à abstinência, à castidade. Em nossa cultura, ela terá sua formulação mais completa em Paulo, um dos principais teóricos do cristianismo. Na Primeira Epístola aos Coríntios, ele aconselha $(6,18)$ : "evitai a fornicação" (pheúgete tèn porneían) e, logo abaixo $(7,1)$, "para um homem, o bom é não tocar em mulher" (kalòn anthrópoi gunaikòs mè háptesthai). Paulo aconselha aos solteiros que permaneçam castos, como ele. Mas, caso lhes seja impossível resistir ao desejo, que se casem: é melhor se casar do que se abrasar (krêtton estin gameîn è puroûsthai 7, 9). Para Paulo, portanto, o ideal é não fazer sexo, resistir ao desejo: um homem virtuoso, um homem de força moral deve permanecer casto. Mas Paulo deixa a possibilidade de uma válvula de escape para os homens que não têm a força moral que ele tem: se não forem capazes de se abster de sexo, que se casem. O sexo é um mal; contudo, a maior parte dos homens não consegue derrotá-lo: nesse caso, que pelo menos o mal seja regularizado por meio do casamento.

Mas, voltando ao Hipólito, seria legítimo formularmos a seguinte questão: no universo trágico grego essa solução - apresentada exemplarmente por Paulo séculos mais tarde - seria possível? De fato, teria sido exatamente essa a solução proposta por Hipólito [aliás, Hipólito é mais radical do que Paulo: para Paulo, o sexo é um mal; para Hipólito, não só o sexo, mas a própria mulher é um grande mal (kakòn méga): num mundo ideal não existiriam mulheres (versos 616ss.)]. Mas no Hipólito tal solução - a abstinência completa de sexo - fracassa. Ao final da tragédia, Hipólito é punido por sua afronta a Afrodite e morre de maneira horrível.

Por que a solução da abstinência não funciona no quadro moral e religioso da tragédia grega? Vimos que no mundo grego o desejo sexual é assimilado a uma doença. Nós padecemos dele, nós o sofremos: ele é um páthos. Padecemos desse desejo como padecemos de uma gripe ou de uma peste. ${ }^{5}$ Contudo, na visão grega pré-platônica, há uma diferença fundamental de perspectiva que exclui, para o homem comum, a solução da abstinência; no mundo grego o desejo erótico é uma doença, sim, mas é uma doença divina: deriva diretamente de Afrodite. No cristianismo (e já em Platão) há uma desqualificação moral do mundo sensível (e do corpo, que é o veículo mesmo de todo o sensível, corpo

${ }^{5}$ Em Lucien Leuwen, o herói de Stendhal, desconfiado de que está amando, se pergunta: Est-ce quej'aurais la peste? (Stendhal, 1973, t. I, pág. 266). 
que incorpora - perdoem-me a redundância - todo o sensível). O corpo é sensível e todo o sensível passa pelo corpo; o corpo é condição necessária do sensível. Platão, contudo, nos diz (e o cristianismo no-lo dirá séculos depois): o real, o verdadeiro, o divino estão além do corpo, não podem ser sentidos pelo corpo. ${ }^{6} \mathrm{O}$ corpo é um túmulo, é a prisão em que nossa alma divina está encarcerada. ${ }^{7} \mathrm{O}$ desejo erótico - que é um desejo desse corpo inferior, ruim, vil - é uma doença a ser enfrentada por meio da abstinência, da castidade; o desejo erótico é só mais uma das misérias da condição humana.

No mundo grego, antes de Platão, tal nósos não era considerada ruim nem abjeta. Ela era um problema, sim, ela incomodava, mas os desejos do corpo não eram moralmente condenados, em bloco, de maneira inapelável. O grego pré-platônico não via o mundo através de uma perspectiva dualista que opõe, por um lado, um mundo sensível, que é inferior e mau, e, por outro lado, um mundo do espírito e do intelecto, que é superior e bom. Podemos afirmar, de modo muito simples, que na cultura grega pré-platônica o mundo sensível também é sagrado (isso é, pertence à ordem do divino, no mesmo plano em que está aquilo que consideramos hoje espiritual ou intelectual) $;^{8}$ podemos afirmar que o desejo sexual é sagrado. Afrodite é a deusa que representa este aspecto divino da condição humana: o sexo. Para Paulo (e para Platão), a castidade do homem comum é uma virtude. No Hipólito de Eurípides, é húbris, é desmedida arrogante, é uma afronta sacrílega a um dos múltiplos aspectos do divino.

Neste ponto o leitor do Hipólito poderia se propor outra questão: não havia, no mundo grego, impedimentos ou restrições à satisfação da

\footnotetext{
${ }^{6}$ É verdade que Platão admitia, com relação aos prazeres do corpo, uma ideia de boa medida. Não o nego: não se trata, em Platão, de impor uma abstinência completa de todos os gozos corpóreos. O que afirmo é que, para Platão, os prazeres do corpo estão num plano moralmente inferior ao plano dos prazeres da alma. Estes têm valor em si mesmos; aqueles, não. Estes são divinos; aqueles não.

${ }^{7}$ No pensamento poético grego, a perspectiva é diferente: aqui, a alma não é um inquilino (ou um prisioneiro) do corpo; é o corpo que é animado. O homem não é uma alma que é prisioneira de um corpo; o homem é um corpo animado.

${ }^{8}$ Essa fratura entre plano o sensível e o plano espiritual-intelectual é estranha ao pensamento poético grego. Se não é invenção platônica, pelo menos encontrou sua formulação mais clara em Platão.

${ }^{9}$ A castidade, contudo, é aceita - e mesmo exigida - em funções sacerdotais específicas em que virgens se dedicam exclusivamente ao serviço de certos deuses. São exceções regulamentadas, que não se aplicam ao homem comum.
} 
paixão erótica? Trata-se, então, de uma cultura em que o sexo era totalmente livre? Penso que não - e aqui há, em minha opinião, um ponto importante que distingue, num aspecto essencial, a moral grega da moral cristã. Em suas valorações éticas, a moral cristã é uma moral do "tudo ou nada". O corpo é inferior, a alma é superior, é divina. Os prazeres do corpo são vis, o sexo, em si mesmo, não é um bem. Para Paulo, o homem virtuoso deve se abster de sexo, deve ser casto. Aquela válvula de escape - casar-se - se destina aos moralmente mais fracos. E, mesmo no quadro do casamento, o sexo é tolerado unicamente como um mal necessário, inerente à condição humana - um mal necessário para a procriação e para a constituição da família cristã - e não como fonte legítima de um prazer que tenha valor em si mesmo. Esse dualismo - de um lado tudo aquilo que é bom, nobre, divino; de outro, as coisas reprováveis, pérfidas, moralmente condenadas - não existe na moral grega.

$\mathrm{Na}$ lógica grega, a relação entre o moralmente superior e o moralmente inferior é nuançada: ali, é fundamental a noção de métron, medida, equilíbrio. Hipólito, que é um fanático da castidade, venera absolutamente Ártemis (deusa virgem) e despreza absolutamente Afrodite. Paulo consideraria a atitude de Hipólito virtuosa; um grego do século $\mathrm{V}$ a.C., não: na atitude de Hipólito não há medida, não há equilíbrio entre esses dois aspectos divinos de nossas existências Afrodite e Ártemis, sexo e castidade. Adotar visceralmente um extremo - seja Afrodite, seja Ártemis - com total desprezo pelo outro não é virtude; é húbris.

Na moral cristã há um único deus, uma única verdade, um único bem. Na moral grega pré-platônica, há muitos deuses, que recobrem todos os aspectos da condição humana - do homem concreto, compreendido como um corpo no mundo - e lhes conferem um caráter sagrado. Há muitas verdades, com muitas facetas, e o bem pode ter muitas formas: consiste em inúmeras possibilidades de equilíbrio entre todos os aspectos da condição humana. Entre a bacanal perpétua e desenfreada e o fundamentalismo casto de Hipólito, há múltiplas soluções de equilíbrio e compromisso; entre o sexo - que é divino - e a castidade - que é divina - há soluções moralmente legítimas para os homens reais, de carne e osso, que somos nós. Uma dessas possíveis soluções de equilíbrio e compromisso é dada, no Hipólito, pelo servo que admoesta o herói ao ver que ele reverencia Ártemis e ignora acintosamente Afrodite. Dialogam assim o servo e Hipólito (versos 103ss.): ${ }^{10}$

${ }^{10}$ Tradução minha; cf. Referências. 
SERVO - Tem mais juízo, que hás de ser feliz.

HIPÓLITO - Desprezo um deus que à noite causa pasmo.

SERVO - É necessário honrar os deuses, filho.

No ponto de vista do homem comum, é preciso honrar os deuses - todos eles. E Afrodite é uma deusa.

\section{Referências}

DA PONTE, L. Tre libretti per Mozart. Le nozze di Figaro, Don Giovanni, Così fan tutte. Milano: Rizolli, 1990.

EURIPIDES. Hippolytus. Edited with introduction and commentary by W. S. Barret. Oxford: Clarendon Press, 1964.

. Hipólito. Tradução, introdução e notas de Flávio Ribeiro de Oliveira. São Paulo: Odysseus, 2010.

HOMERI. Opera. Oxford: Clarendon Press, 1963.

LONGINO. Libellus de sublimitate. Oxford: Clarendon Press, 1968.

Nouum testamentum. Apparatu critico instructum edidit Augustinus Merk S.J. Roma: Sumptibus Pontificii Instituti Biblici, 1951.

PLATONIS. Opera. Recognouit breuiqueadnotatione critica instruxit Ioannes Burnet. Oxford: Clarendon Press, 1903. Tomus III.

SAPPHO; ALCAEUS. Fragmenta. Edidit Eva-Maria Voigt. Amsterdam: AthenaeumPolak \& Van Gennep, 1971.

STENDHAL. Lucien Leuwen. Paris: Gallimard, 1973.

Recebimento contínuo - Aceite: 15 de maio de 2011 